$\sqrt{3}$

J. bio-sci. 19: 29-35, 2011

ISSN 1023-8654

http://www.banglajol.info/index.php/JBS/index

\title{
DISTRIBUTION OF STARCH, LIPID AND NUCLEI IN XYLEM AND PHLOEM OF TECTONA GRANDIS LINN.
}

\author{
Md Azharul Islam ${ }^{1 *}$, Shahanara Begum² \\ ${ }_{1}^{1}$ Graduate Training Institute, ${ }^{2}$ Deaprtment of Crop Botany, Faculty of Agriculture, Bangladesh Agricultural \\ University, Mymensingh, Bangladesh
}

\begin{abstract}
Context: Reserve materials among different plant tissues vary species to species. The distribution pattern of such materials and cell death pattern in Tectona grandis Linn. are still obscure.

Objectives: To study the localization of starch, lipid and nuclei in the phloem, cambium and xylem tissue of $T$. grandis.

Materials and Methods: Blocks containing phloem, cambium and outermost xylem of the stem of 12 years old teak tree collected. Different staining methods used to visualize starch, lipid and nuclei within different cells under light microscope.

Results: Starch in parenchyma cells is more abundant in outer xylem than phloem and cambium. Lipids droplets are uniformly distributed in outermost xylem. Phloem parenchyma content few mass of lipids but, limited in cambium. There are many dead cells visualized in both phloem and xylem with characteristic patterns. The results clarify the levels of starch, lipid in tissue of $T$. grandis and showed distinguished variation among the cell contents.

Conclusion: The physiology of plant cells related to transport of nutrients and cell death also illustrated in the report. This would be helpful for further study to improve quality wood through tree breeding program.
\end{abstract}

Keywords: Tectona grandis, Xylem and Phloem, Cambium, Storage materials.

\section{Introduction}

Teak is the common name for the tropical heartwood tree species Tectona grandis Linn. (Fam. Verbenaceae) and one of the famous for its wood products (Cantino 1992). T. grandis is native to south and Southeast Asia, mainly India, Indonesia, Malaysia, and Burma, but is naturalized and cultivated in many countries, including those in Africa and the Caribbean. Teak is a yellowish brown timber with good grains and texture. It is used in the manufacture of outdoor furniture, boat decks, and other articles where weather resistance is desired.

It was reported that stored materials are crucial to radial growth, wood density and formation of the current year's tree ring. There have been several reports of variations in levels and partitioning of storage starch granules, lipid droplets in trees, e.g. Betula pendula (Harms and Sauter 1992), Pinus sylvestris (Fischer and Höll 1992); Juglans nigra and hybrid Juglans major × J. regia (Magel et al. 2001), Pinus cembra (Hoch et al. 2002), Quercus petraea and Fagus sylvatica (Barbaroux and Breda 2002, Barbarous et al. 2003). The data in the cited studies indicate that levels of different reserve materials from phloem to xylem provides one of the key to a full understanding of growth and development of trees.

Histochemical studies of the transition from sapwood to heartwood in $T$. grandis reported by Datta and Kumar (1987). They emphasized on localization of starch, lipids, proteins, nucleic acids and phenolics, where showed significant changes during transition. It is found lack of knowledge on histological features of $T$. grandis phloem and xylem tissues in all studies. So, the present study describes the distribution, availabilities, pattern of storage starch and lipid from phloem to xylem part using histochemical parameters. This report also explains the presence or absence of nuclei within the cell in relation to study cell death and their patterns.

‘Corresponding author Email: islam162@yahoo.com 


\section{Materials and Methods}

Wood Blocks containing outer bark, phloem, cambium and xylem from teak plant (T. grandis) were collected from Bangladesh Agricultural University campus, Mymensing in April 2011. Samples were protected from moisture and light using aluminum paper. Immediately samples were fixed in $4 \%$ glutaraldehyde and transported to the Laboratory of Morphogenesis and Plant Resources, Tokyo University of Agriculture and Technology, Japan. Fixed samples were washed in $0.1 \mathrm{M}$ phosphate buffer and trimmed to $3 \mathrm{~mm}$ for subsequent fixation in $1 \%$ osmium tetraoxide in $0.1 \mathrm{M}$ phosphate buffer for $2 \mathrm{~h}$ at room temperature. After washing, specimens were dehydrated in a graded ethanol series and embedded in epoxy resin. Transverse sections were cut at a thickness of approx. $2 \mu \mathrm{m}$ with a glass knife on an ultramicrotome (Ultracut $\mathrm{N}$; Reichert, Vienna, Austria). Sections were stained with a solution of $1 \%$ safranin in water for observations of anatomical features of tissues of phloem, xylem and cambium and then examined under a light microscope (Axioscop; Carl Zeiss, Oberkochen, Germany) (Nakaba et al. 2008, 2012).

Sections (radial, transverse, and tangential) were cut at a thickness of approx. $40 \mu \mathrm{m}$ with a stainless steel microtome blade on the freezing stage of a sliding microtome (MA-101; Komatsu Electronics, Tokyo, Japan). For light microscopic observations of storage starch, sections were stained with iodine-potassium iodide $\left(I_{2}-\right.$ $\mathrm{KI}$ ) for 2-3 min (Nakaba et al. 2006, Begum et al. 2007). After staining, sections were washed with distilled water. For visualization of lipid droplets, sections were washed in series of ethanol (from 30\% to $70 \%$ ) followed by stained with Sudan Black B in 70\% ethanol for 5 min. After staining, sections were washed with $70 \%$ ethanol for 2-3 min. Sections were stained with acetocarmine followed by washing with distilled water two time and then series of ethanol (from $30 \%$ to $100 \%$ ethanol) to visualize nuclei under the light microscope (as above).

\section{Results}

Anatomical observations of teak sample - Outer xylem cells are mostly living cells and active in natural function for plant growth and development. There was few xylem parenchyma cells visualized clearly using safranin stain for tangential sections under light microscope (Fig. 1ab). Most of the xylem ray cells were rich in storage materials that were dark coloured during observation. Phloem and xylem tissue were observed under light microscope with safranin stain in transverse section. The observation focused on natural tissue arrangement and chronological alignment from phloem to cambium tissue then outer xylem cells of a teak tree. There are many variations between the tissues visualized as well as their cell size, shape and variation in between different portions (Fig. 1C). The outer bark of the plant parts is mostly composed of dead cell and the dark coloured observations appeared followed by phloem parenchyma cells in inner bark of phloem tissues (data not shown). Inner part of phloem mostly composed of live parenchyma cell and those are dark coloured phloem fibre due to containing more food materials (Fig. 1c). A cambial zone (black arrowhead) visualized in between phloem and xylem cells. The lighter colour of cambial zone is very narrow, which is more important for growth and development of plant and to form more xylem tissue in period of time (Fig. 1C). Xylem parts mostly composed of xylem parenchyma cells and wood fibres. Both tissues are clearly visualized in Fig. 1 (a-c).

The remarkable vessel elements are also observed in new xylem portion and in latewood portion of outer xylem. The prominent thickening of the cell wall of new xylem tissue and latewood xylem cells varies naturally. Cell size, arrangement within phloem, cambial zone and xylem part also varied. Cellular structural variation was observed from phloem to xylem of teak plant under light microscope (Fig. 1). The transverse visualization clarified the cell size, arrangement within phloem to xylem, where phloem ray parenchyma, phloem parenchyma, cambial zone, new xylem tissue, xylem ray parenchyma and xylem parenchyma tissues etc. were illustrated (Fig. 1c). 

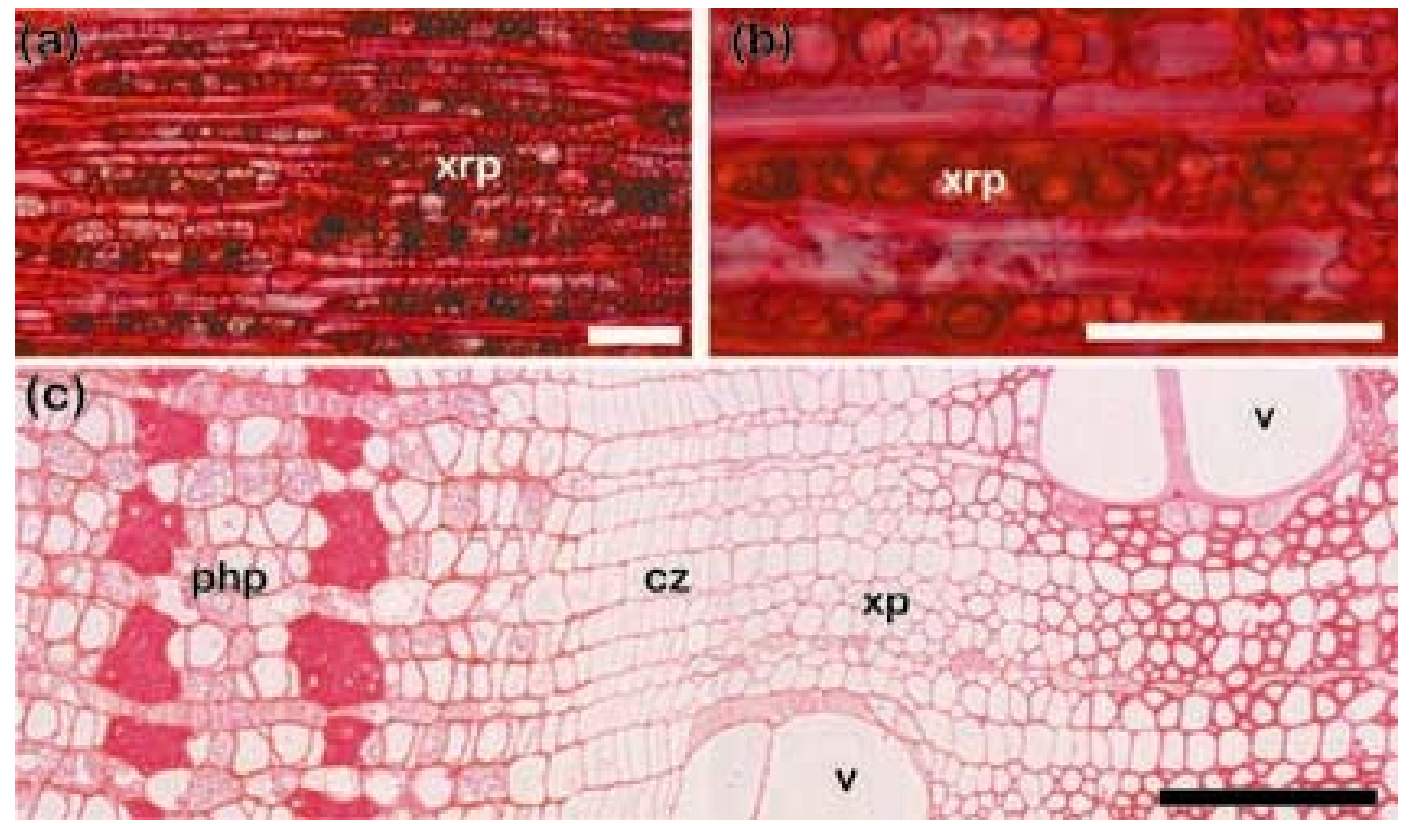

Fig. 1. Light microscopic images (a-b, tangential; c, transverse sections) of tissue of Tectona grandis. (a) different cells of xylem tissue, (b) xylem ray parenchyma cell in higher zoom, (c) ultramicrotomic observation of different cells from phloem to xylem tissue with cambial zone and vessel elements. Abbreviations: xrp, xylem ray parenchyma; php, phloem parenchyma; $c z$, cambial zone; $x p$, xylem parenchyma; $v$, vessel; scale bars $25 \mu \mathrm{m}$.

Visualization of Starch granules - Starch grains were localized with the $\mathrm{I}_{2}-\mathrm{KI}$ reaction, observed as black grain/granules like structure within the cells. Starch grains in the ray parenchyma cells were more abundant than other cells. Both axial and ray parenchyma of outer sapwood contain starch granules (Fig. 2). Almost different angular observations (e.g. radial, transverse and tangential) showed the clear visualization of starch content inside the cells. Among them radial observation (Fig. 2A) provide more clear visualization than transverse section (Fig. 2B) followed by tangential section (Fig. 2C). The vessels and their surrounding cells contain much starch granules observed in transverse (Fig. $2 \mathrm{~B}$ ) only. The xylem ray parenchyma cells of the outer sapwood part of the teak stem are mostly rich in starch grains.

The radial observation of starch localization from phloem to outer xylem was depicted in Fig. 3. In phloem, the occurrence of starch is relatively smaller than xylem portion. Since the outer bark contains dead cell, so that most of the cells were devoid of starch granules (Fig. 3a). In inner bark, limited amount of starch granules also visualized in some phloem parenchyma cells (Fig. 3a). The innermost phloem parenchyma cells contain considerable starch granules (Fig. 3b). Phloem parenchyma cells content starch grains (Fig. 3c) but not like more as outer xylem ray parenchyma cells (Fig. 3d). There was limited starch grains observed in cambial zone in between phloem and xylem tissue (Fig. 3e). Most of the phloem tissue (ray and fibre) near to cambial zone content enough starch grains but those storage starch grains were utilized in cambial zone for their activation in growing season of plants. On the other hand newly formed xylem tissue and all of the xylem ray cells content enough storage starch (Fig. 3e). Almost all of the living cells contains starch particles, on the other hand no starch available in wood fibre tissue in xylem. The abundant starch granules stored in xylem ray parenchyma cells as well as ray trancheids (Fig. $3 \mathrm{f}-\mathrm{g}$ ).

Nuclei: The presence of nuclei helped to distinguish dead and live cells. Using acetocarmine stain, nuclei of live cells were observed as small reddish spots (arrows showed the nuclei) (Figs. 4 and 5). Live cells under 
three different angular observations (radial, transverse and tangential) content their marked nuclei (Fig. 4). Outer bark of the teak tissues has no nuclei since those are dead cells (Fig. 5A). Inner bark of investigated sample were almost phloem parenchyma cells the all of the cells contain nuclei (Fig. 5A-B). Phloem ray parenchyma (prp) cells contain their nuclei to show their liveliness (Fig. 5B). On the other hand wood fibre cells are devoid of nuclei as they were dead earlier. Cells of cambial zone were active and live, where regulate the growth and development of new tissue. Xylem ray parenchyma (xrp) also showed the presence of nuclei inside of cells (Fig. 5B-D). Rather than ray parenchyma cells of xylem part, the ray trachieds also content their nuclei (Fig. 5C-D).

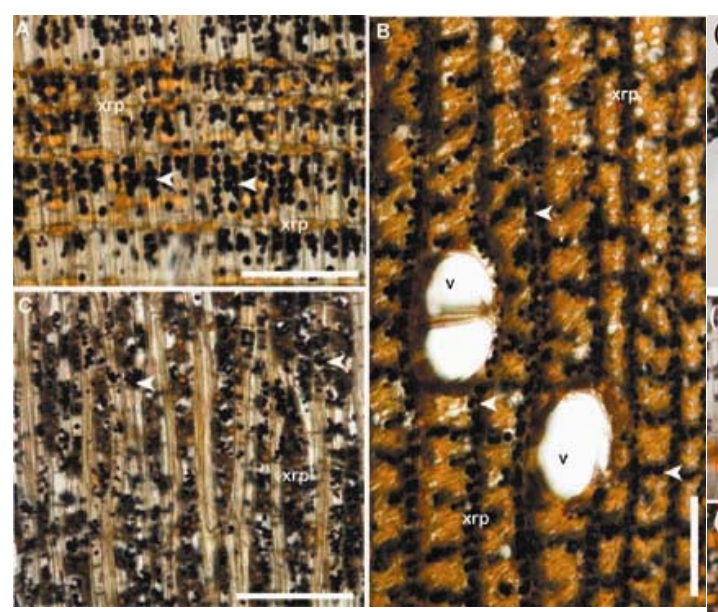

Fig. 2. Light microscopic observation showing radial (a), transverse (b) and tangential (c) view to localize storage starch (arrows) around outer xylem of $T$. grandis stem. Abbreviations: xrp, xylem ray parenchyma; v, vessel. Scale bars $=50 \mu \mathrm{m}$
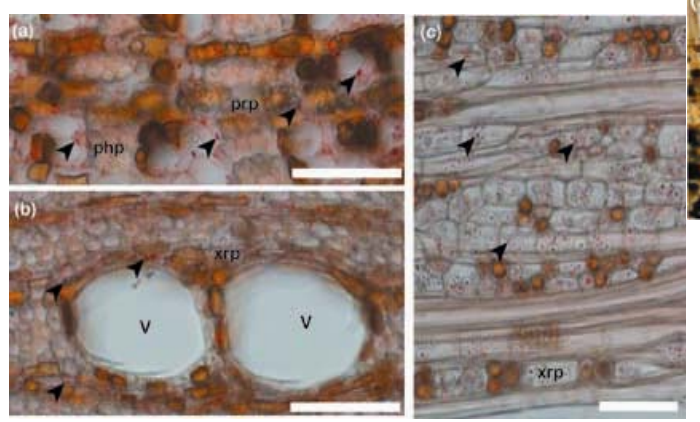

Fig. 4. Nuclei visualization (using acetocarmine stain) under light microscope showing radial (a), transverse (b) and tangential (c) views in phloem (a) and outer xylem tissue $(b, c)$ of $T$. grandis stem. Abbreviations: php, phloem parenchyma; prp, phloem ray parenchyma, xrp, xylem ray parenchyma; v, vessel. Scale bars = $50 \mu \mathrm{m}$ Lipids: Lipids, localized with the Sudan Black B reaction, appeared like droplets (arrowheads) in phloem tissue (Fig. 6a) and those are limitedly appeared in the middle of phloem (Fig. 6b). The phloem ray parenchyma cells have no deposition of remarkable lipid droplet. The ray parenchyma cells of the xylem part
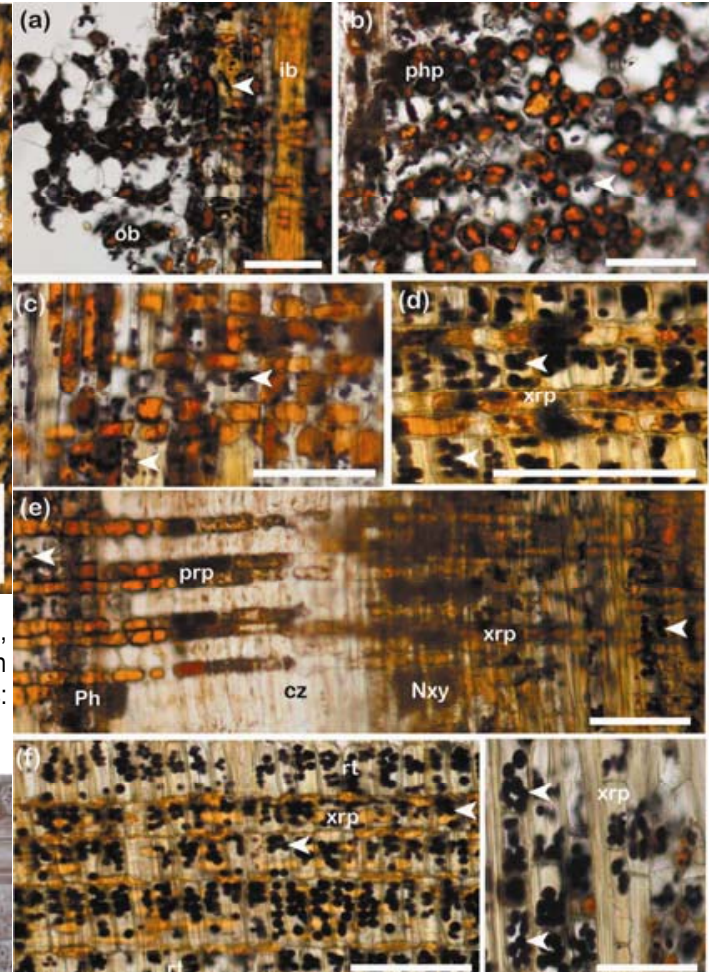

Fig. 3. Radial visualization of starch from phloem to xylem tissue of $T$. grandis under light microscope. (a) limited storage starch in outer phloem part, (b) storage starch evident in mid phloem parenchyma cells, (c) limited starch in phloem parenchyma cell, (d) abundant starch appeared in xylem ray parenchyma cells, (e) cambial zone with surrounding phloem and xylem having starch localization, (f) abundant storage starch in the xylem ray cells of outer sapwood, (g) abundant storage visualized around the xylem ray cells of mid sapwood. Arrowheads indicate starch granules. Abbreviations: ob, outer bark; ib, inner bark; php, phloem parenchyma; $\mathrm{Ph}$, Phloem tissue; prp, phloem ray parenchyma; $\mathrm{cz}$, cambial zone; Nxy, New xylem tissue; xrp, xylem ray parenchyma; rt, ray trachied. Scale bars $=50 \mu \mathrm{m}$ 
have remarkable lipid bodies than the phloem tissue (Fig. 6c). Those were fully absent in current year xylem tissue but the uniform distribution was noted from second growth ring to inside of xylem (Fig. 6c). Most of the cases their appearance observed in mass of droplets or cluster like (Fig. 6a-c) during radial observation. Only xylem ray parenchyma cells showed with lipid droplets in tangential observation (Fig. 6d). In case of transverse visualization, lipid droplets mainly deposited all of the secondary xylem cells and around the vessel surrounding parenchyma cells (Fig. 6e).
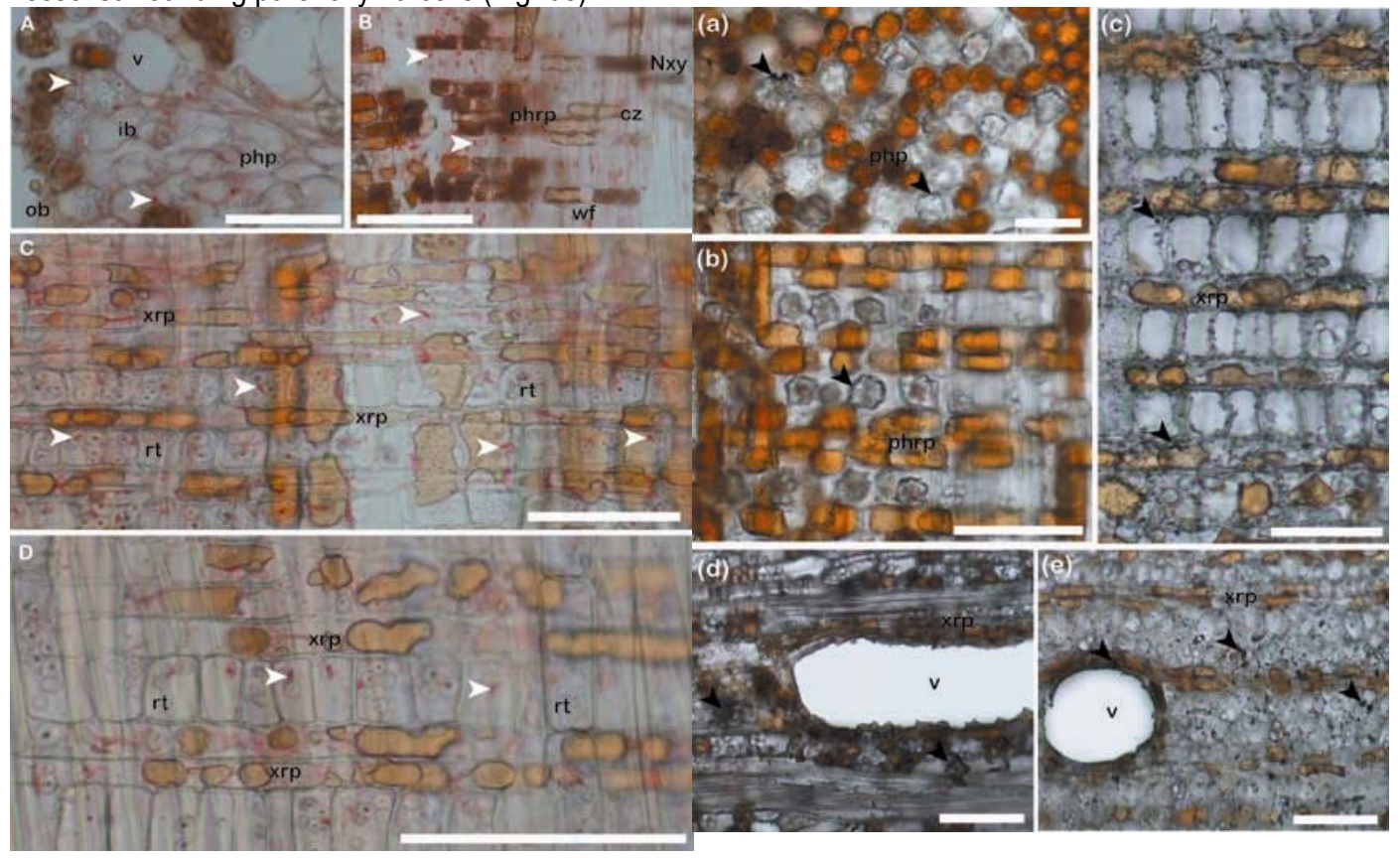

Fig. 5. Radial observation of nuclei of teak stem tissue under light microscope, stained with acetocarmine. (a) Phloem part with outer and inner bark tissue, (b) Cambial zone with phloem and new xylem tissues, (c-d) Ray cells of outer xylem tissue, Arrowheads indicated nuclei. Abbreviations: ob, outer bark; php, phloem parenchyma; ib, inner bark; $v$, vessel; phrp, phloem ray parenchyma; wf, wood fiber; cz, cambial zone, Nxy, new xylem xrp, xylem ray parenchyma; rt, ray trachied; scale bars $=50 \mu \mathrm{m}$.

Fig. 6. Teak stem tissue after visualization for lipid under light microscope (stained with Sudan Black B); radial (a-c), tangential (d) and transverse (e). (a) Inner phloem tissue with limited lipid droplets, (b) no considerable lipid droplets in phloem ray parenchyma cells, (c) limited protein droplets in outer xylem parenchyma tissue, (d) Earlywood of xylem ray cells with vessel surrounded by lipid droplets, (f) Outer xylem ray cells content limited lipid droplets. Arrowheads indicated visualized lipid drop/droplets. Abbreviations: php, phloem parenchyma; phrp, phloem ray parenchyma; xrp, xylem ray parenchyma; v, vessel; scale bars $=50 \mu \mathrm{m}$

\section{Discussion}

The present study attempts to relate the structural observations on phloem and xylem tissue with their starch, lipid distribution and availability of nuclei. The changes on distribution and localization of storage starch in the phloem and outer xylem occurred. In the outer part of phloem no such starch particles localized, increased inside of phloem tissues. In xylem tissue almost all of the ray parenchyma and axial parenchyma tissue contain much storage starch more in relation to phloem parenchyma tissue. There was no considerable starch localization occurred in wood fibre rather than ray and axial cells. The variability of both lipid and protein droplets observed between phloem and xylem tissue. These results emphasized on the results reported by Begum et al. (2010), starch and lipid droplets must be needed as a source of energy for the 
initiation of cambial cell division and xylem differentiation in Cryptomeria japonica. The present results showed clearly that, the level of starch in phloem falls significantly at the start of xylem differentiation. In Larix kaempferi the maximum starch granules observed in sapwood, mostly outer to middle part and most starch grains were localized in middle lines of parenchyma cells rather than upper and lower lines (Islam et al. 2012).

The abundance of starch granules in phloem and cambium decreased from cambial reactivation to xylem differentiation in stems of Tectona grandis. A marked change of starch granules was also observed in phloem ray parenchyma cells and longitudinal phloem parenchyma cells during xylem differentiation. The decreases of starch granules were closely related to the change in their levels. Therefore, the reduced starch granules in phloem and cambium might provide energy during cambial reactivation and xylem differentiation (Begum et al. 2010).

Hillinger et al. (1996) observed that lipid droplets accumulated mainly in the cambium and the level of lipids (as droplets) fell steadily as the distance from the cambium to the phloem and xylem increased during cambial dormancy in Robinia pseudoacacia. Similarly, in the present study of teak trees, the relative area occupied by lipid droplets was higher in the cambium than in the phloem and this area remained unchanged in phloem ray parenchyma cells and longitudinal phloem parenchyma cells. Fischer and Höll (1992) and Sauter and van Cleve (1994) proposed that the storage lipids in the secondary xylem ray parenchyma cells might be generated from sugars or from starch and that the small-scale conversion of starch to lipids might occur in the autumn in Scots pine and poplar trees, respectively. In addition, Sauter and van Cleve (1994) reported that, in the secondary xylem ray parenchyma cells that were located close to the cambium of poplar trees (Populus $\times$ Canadensis), there were clear reductions in levels of lipids (as droplets) from cambial reactivation to the start of xylem differentiation. Therefore, these authors postulated that lipid droplets might be mobilized for the production of new cells in this variety of poplar in spring time.

\section{Conclusion}

The pattern of distribution of storage materials in phloem, cambium and outer xylem in a $T$. grandis stem showed the positional importance in relation to nutrients availability. Considering the prominent changes in starch and lipid within phloem and xylem and their use in active cambial zone, it appeared interesting to search for a relationship between ultra structural data and biochemical phenomena in ray cells. In addition, an attempt is made to follow the changes of storage materials, the cell death between phloem and xylem parts in relation to the ultrastructure of these cells. Therefore, the findings may be suggested the variation of storage materials is an indicator of the activity of cells during plant growth and development.

\section{Acknowledgement}

The authors are grateful to Professor Dr Ryo Funada and Assistant Professor Dr Satoshi Nakaba of Tokyo University of Agriculture and Technology, Japan for laboratory facilities to do microscopic studies and their scholastic suggestion.

\section{References}

Barbaroux C, Breda N, Dufrene E. 2003. Distribution of above-ground and below-ground carbohydrate reserves in adults trees of two contrasting broad-leaved species (Quercus petraea and Facus sylvatica). New Phytologists 157, 605-615. http://dx.doi.org/10.1046/j.1469-8137.2003.00681.x

Barbaroux C, Breda N. 2002. Contrasting distribution and seasonal dynamics of carbohydrate reserves in stem wood of adult ringporous sessile oak and diffuse-porous beech trees. Tree Physiol 22, 1201-1210. http://dx.doi.org/10.1093/treephys/22.17.1201 PMid: 12464573

Begum S, Nakaba S, Oribe Y, Kubo T, Funada R. 2007. Induction of cambial reactivation by localized heating in a deciduous hardwood hybrid poplar (Populus sieboldii $\times$ P. grandidentata). Ann Bot 100, 439-447. http://dx.doi.org/10.1093/aob/mcm130 PMid:17621596 PMCid:2533603 
Begum S, Nakaba S, Oribe Y, Kubo T, Funada R. 2010. Cambial sensitivity to rising temperatures by natural condition and artificial heating from late winter to early spring in the evergreen conifer Cryptomeria japonica. Trees 24, 43-52. http://dx.doi.org/10.1007/s00468-009-0377-1

Cantino PD. 1992. Genera of Labiatae: status and classification. In: Harley RM, Reynolds T. (eds.), Advances in labiate science, (Adv Lab Sci). pp. 511-522.

Datta SK, Kumar A. 1987. Histochemical studies of the transition from sapwood to heartwood in Tectona grandis. IAWA Bull 8(4), 363368.

Fischer C, Höll W. 1992. Food reserves of Scots pine (Pinus sylvestris L). 2. Seasonal changes and radial distribution of carbohydrate and fat reserves in pine wood. Trees 6,147-155.

Harms U, Sauter JJ. 1992. Changes in content of starch, protein, fat and sugars in the branchwood of Betula pendula Roth during fall. Holzforchung 46, 455-561. http://dx.doi.org/10.1515/hfsg.1992.46.6.455

Hillinger C, Höll W, Ziegler H. 1996. Lipids and lipolytic enzymes in the trunkwood of Robinia pseudoacacia L. during heartwood formation. 1. Radial distribution of lipid classes. Trees 10,366-375. http://dx.doi.org/10.1007/BF02185640

Hoch G, Popp M, Korner C. 2002. Altitudinal increases of mobile carbon pools in Pinus cembra suggests sink limitation of growth at the Swiss treeline. Oikos 98, 361-374. http://dx.doi.org/10.1034/j.1600-0706.2002.980301.x

Islam MA, Begum S, Nakaba S, Funada R. 2012. Distribution and Pattern of availability of Storage starch and cell death of Ray parenchyma cells of a Conifer Tree (Larix kaempferi). Res J Recent Sci 1(5), 28-37

Magel E, Abdel-Latif A, Hampp R. 2001. Non-structural carbohydrates and catalytic activities of sucrose-metabolizing enzymes in trunks of two Juglans species and their role in heartwood formation. Holzforschung 55, 135-145. http://dx.doi.org/10.1515/HF.2001.022

Nakaba S, Sano Y, Kubo T, Funada R. 2006. The positional distribution of cell death of ray parenchyma in a conifer, Abies sachalinensis. Plant Cell Rep 25, 1143-1148. http://dx.doi.org/10.1007/s00299-006-0194-6 PMid:16799806

Nakaba S, Yamagishi Y, Sano Y, Funada R. 2012. Temporally and spatially controlled death of parenchyma cells involved in heartwood formation in pith regions of branches of Robinia pseudoacacia var. inermis. J. Wood Sci 58(1), 69-76. http://dx.doi.org/10.1007/s10086-011-1221-y

Nakaba S, Yoshimoto J, Kubo T, Funada R. 2008. Morphological changes in the cytoskeleton, nuclei and vacuoles during the cell death of short-lived ray tracheids in the conifer Pinus densiflora. J Wood Sci 54, 509-514. http://dx.doi.org/10.1007/s10086-008-0971-7

Sauter JJ, van Cleve B. 1994. Storage, mobilization and interrelations of starch, sugars, protein and fat in the ray storage tissue of poplar trees. Trees 8, 97-304. http://dx.doi.org/10.1007/BF00202674 